
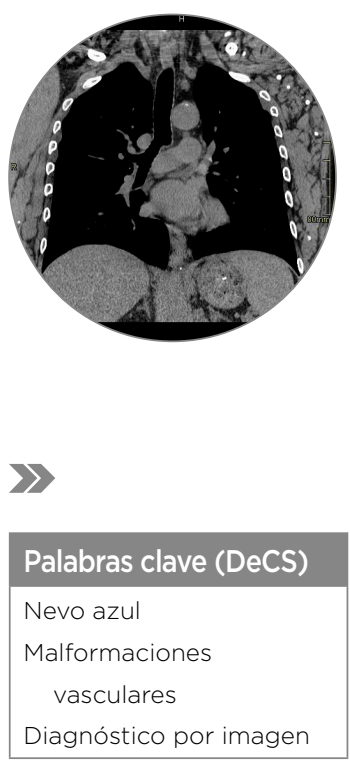

Key words (MeSH)

Nevus, blue

Vascular malformations

Diagnostic imaging
'Radiólogo, Departamento de Imágenes Diagnósticas, Fundación Santa Fe de Bogotá. Bogotá, Colombia.

${ }^{2}$ Residente de Radiología, Departamento de Imágenes Diagnósticas, Fundación Santa Fe de Bogotá. Bogotá, Colombia.

${ }^{3}$ Asistente de investigación, Departamento de Imágenes Diagnósticas, Fundación Santa Fe de Bogotá. Bogotá, Colombia.

\title{
Manifestaciones radiológicas del síndrome del nevus azul. Presentación de caso
}

\author{
Radiological findings of blue nevus syndrome. A case report
}

Gustavo Adolfo Triana Sergio Valencia ${ }^{2}$

Paula Andrea Forero ${ }^{3}$

\section{Resumen}

El síndrome del nevus azul es una entidad infrecuente que consiste en múltiples malformaciones venosas que comprometen la piel y el resto de los órganos. Los pacientes pueden ser asintomáticos o pueden cursar con diversas manifestaciones dependiendo del lugar donde se encuentren estas alteraciones vasculares. Las distintas modalidades diagnósticas permiten identificar claramente las malformaciones vasculares; sin embargo, usualmente son consideradas un hallazgo incidental y rara vez son el motivo de la realización del estudio. A continuación, se describe el caso de un paciente de 65 años de edad con diagnóstico de síndrome del nevus azul, con malformaciones venosas evidentes, en modalidades como tomografía computarizada, ultrasonido y resonancia magnética.

\section{Summary}

The blue rubber bleb nevus syndrome is a rare vascular disorder entity that consists of multiple venous malformations that involve the skin, gastrointestinal tract and viscera. Patients may be asymptomatic or may present with various manifestations depending on the site of these vascular alterations and organs involved. The different diagnostic modalities allow for clear identification of vascular malformations; however, they are usually considered an incidental finding and are rarely the reason for the study to be performed. We describe the case of a 65-year-old patient with a diagnosis of blue nevus syndrome with evident venous malformations in computed tomography, ultrasound and magnetic resonance imaging.

\section{Introducción}

El síndrome del nevus azul, también conocido como síndrome de Bean, es una enfermedad infrecuente que se caracteriza por malformaciones venosas en la piel y las vísceras, dentro de las cuales la localización más común es el tracto gastrointestinal (1). Las lesiones macroscópicas incluyen un espectro de morfologías diferentes; sin embargo, se conoce que con el paso del tiempo aumentan tanto en tamaño como en número; pueden producir en algunos casos episodios de sangrado (2). Los nevus pueden ser congénitos o aparecer de manera tardía y usualmente no están ligados a un patrón genético específico, aunque se han descrito casos de expresión autosómica dominante (3). Por lo general, este síndrome afecta en igual proporción a hombres y mujeres; hay una ligera predominancia en los caucásicos, aunque es posible encontrar este síndrome en todas las razas (4).

A continuación, se presenta el caso de un paciente de 65 años de edad con antecedente de nevus azul y múltiples malformaciones venosas en el organismo.

\section{Caso clínico}

Paciente masculino de 65 años de edad, quien asistió ambulatoriamente al servicio de imágenes diagnósti- cas para la realización de una ecografía de cuello debido a la presencia de una masa en la región supraclavicular izquierda, que correspondía a un quiste de inclusión epidérmica. Adicionalmente, se encontraron hallazgos consistentes con malformaciones vasculares de bajo flujo con numerosos sacos venosos y flebolitos que se extendían hasta la región retropectoral ipsilateral (figura 1). Al interrogatorio, el paciente refirió antecedente de nevus azul y entre sus estudios previos se evidenciaron también malformaciones vasculares en el miembro superior izquierdo (figura 2), en la pared torácica (figura 3 ), en el retroperitoneo (figura 4) y en el cuello (figura 5). Algunas de estas malformaciones eran visibles al examen físico como lesiones redondeadas de coloración violácea en los miembros superiores y el dorso.

Debido a lo anterior, se consideró como impresión diagnóstica síndrome del nevus azul.

\section{Discusión}

El primer caso del síndrome del nevus azul fue descrito por Gascoyen en 1860 y, posteriormente, Bean, en 1958, lo terminó de caracterizar. Por esta razón también se conoce como síndrome de Bean (1), el cual consiste en un espectro de malformaciones vasculares en la piel y, simultáneamente, en cualquier otro órgano 
del cuerpo humano, con frecuencia en el tracto gastrointestinal, lo que conlleva que la sintomatología varíe dependiendo de su localización (1). En lo que respecta a las lesiones de la piel, estas se pueden presentar como una estructura desfigurante que en ocasiones aumenta de tamaño hasta comprimir órganos adyacentes (tipo I); como un saco de coloración azulada, con textura que semeja al caucho y compresible (tipo II); también, como una mácula o pápula de color azul o negro (tipo III) (1). Suelen estar presentes desde el nacimiento o desde la infancia, aunque las malformaciones extracutáneas pueden tardar un poco más en aparecer (2). En el paciente de este caso, sus lesiones concuerdan con un tipo II, distribuidas en miembros superiores y dorso.

Para caracterizar el síndrome se usan diversas ayudas diagnósticas. En las manifestaciones musculoesqueléticas y cutáneas, como en el caso aquí descrito, se ha demostrado la utilidad de la ecografía con Doppler y la resonancia magnética (RM), y esta última es la ideal para evaluar el compromiso de los tejidos óseos y musculares adyacentes a las lesiones (5). En la RM estas malformaciones se observan como estructuras bien definidas, de señal intermedia similar a la del músculo en secuencias con información T1 y de alta señal en secuencias con información T2, con un realce prominente ante la administración de medio de contraste. Adicionalmente, es posible encontrar trombos o flebolitos que se identifican como vacíos de señal focales (5). Los flebolitos, en general, representan una clave diagnóstica para malformaciones venosas (6). En cuanto a la

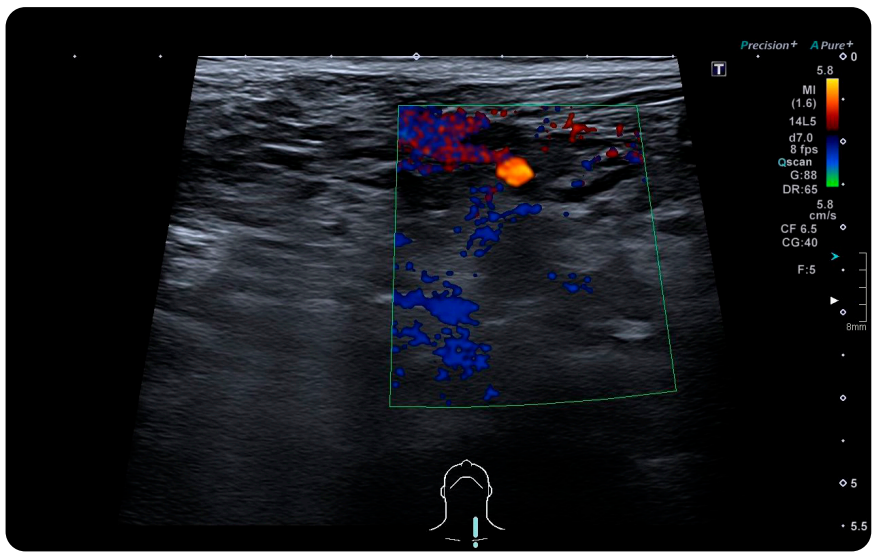

ecografía, se identifican como lesiones hipoecogénicas, compresibles, sin flujo o con flujo monofásico de baja velocidad en el Doppler (6).

Entre los estudios del paciente había una tomografía axial computarizada (TAC) de tórax, la cual se realizó por dolor en hemitórax izquierdo. Allí se evidenciaron múltiples calcificaciones en los tejidos blandos en las regiones supraclavicular, pectoral mayor, axilar derecha y en relación con el músculo dorsal ancho de ambos lados. Lo anterior, en relación con los flebolitos. De igual manera, en la ecografía del cuello, adyacente al quiste de inclusión epidérmica, se evidenciaron imágenes lacunares hipoecogénicas que a la exploración con Doppler mostraban flujo lento y flebolitos. En la RM de abdomen se visualizó una masa de apariencia quística adyacente al hilio renal izquierdo, con ligero realce con el medio de contraste. También, tanto en la Angio-RM de miembro superior izquierdo como en la RM de cuello se evidenciaron las dilataciones saculares que infiltraban el músculo y el tejido celular subcutáneo.

En cuanto al tratamiento, este depende del tamaño, del número y de la localización de las lesiones (7), por lo que debe ser un abordaje individualizado. Una opción es la resección quirúrgica, la cual se realiza con fines estéticos o en casos en los que produzca dolor. Esta alternativa se prefiere en lesiones pequeñas $(2-4 \mathrm{~cm})$ que no invaden otras estructuras, sino que son superficiales; aunque, en algunos casos en que estas condiciones no se cumplan, se puede optar por una embolización previa.
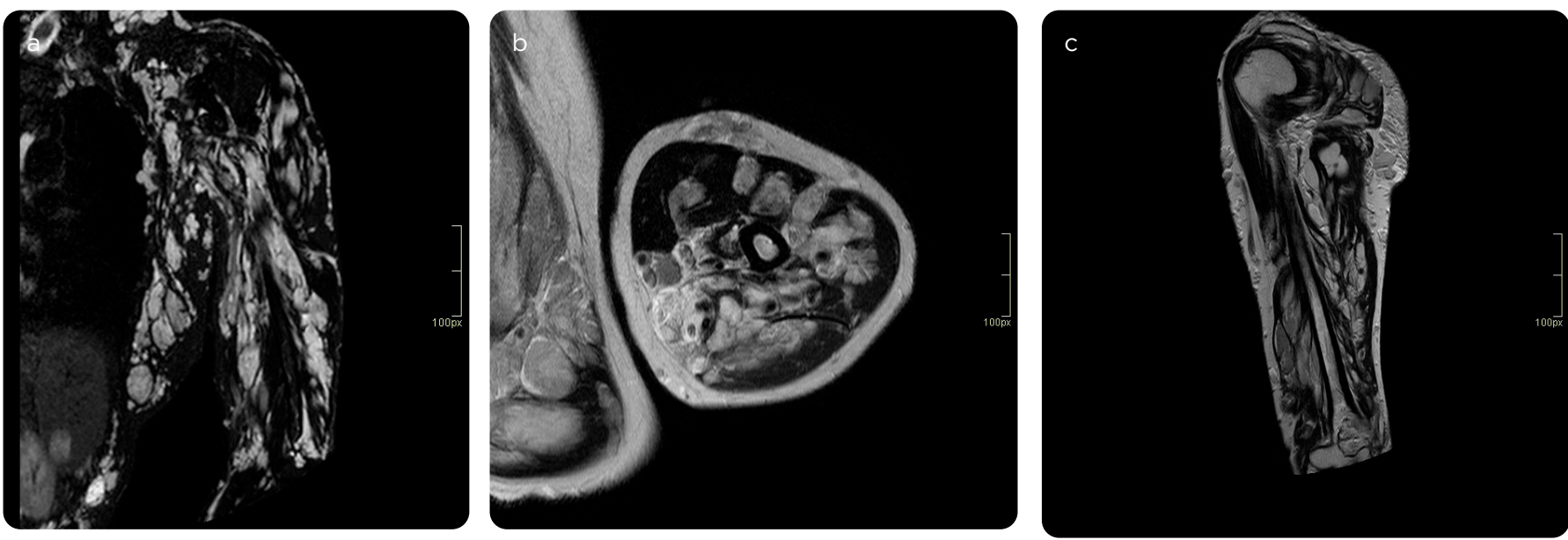

Figura 2. RM de miembro superior izquierdo. a) Vista coronal en secuencia STIR: múltiples áreas de alta señal, de forma sacular, que comprometen el tejido celular subcutáneo y los planos musculares del brazo y de la pared torácica izquierda, con extensión al cuello. b y c) Vista axial y sagital en secuencia DPI que permite la visualización de flebolitos. 

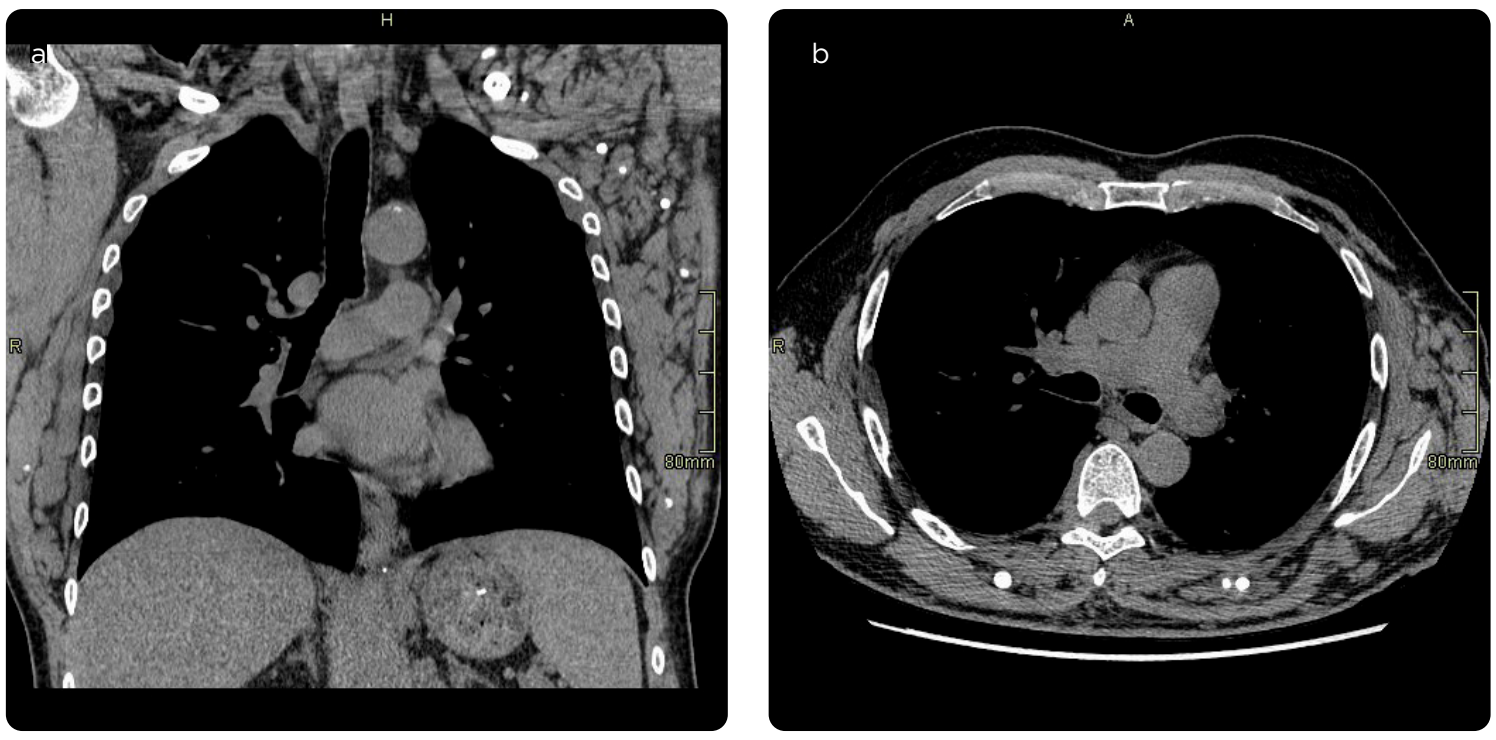

Figura 3. TAC de tórax a) coronal y b) axial: múltiples calcificaciones en los tejidos blandos de la pared del tórax.
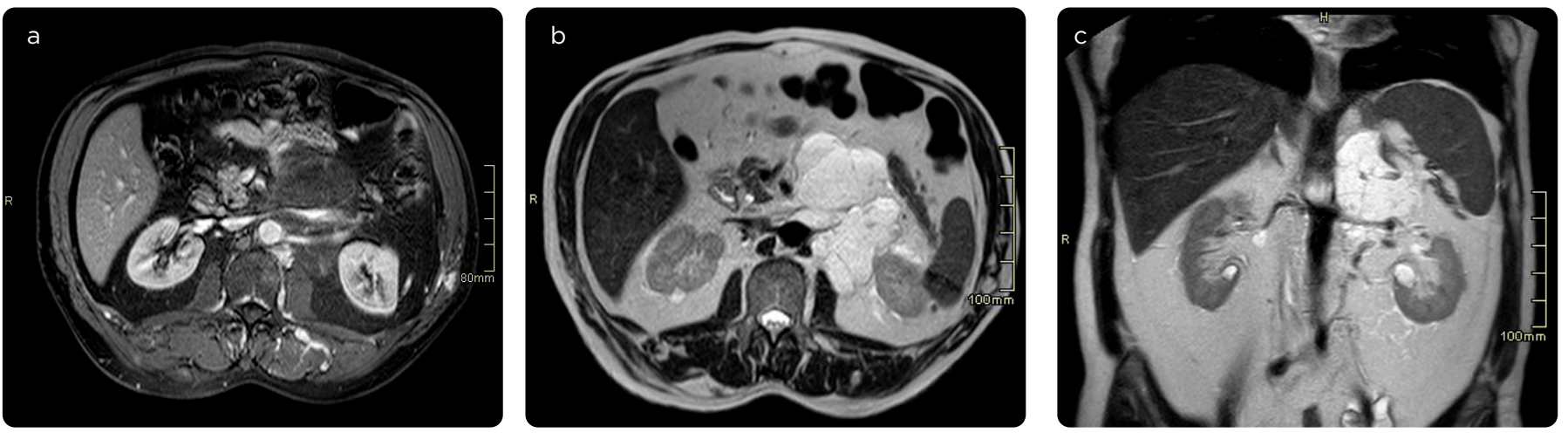

Figura 4. RM de abdomen. a) Axial con información T1 Saturación grasa y con medio de contraste; b y c) RM axial y coronal secuencias con información T2: masa de baja señal en el hilio renal izquierdo que envuelve la vena y la arteria renal.
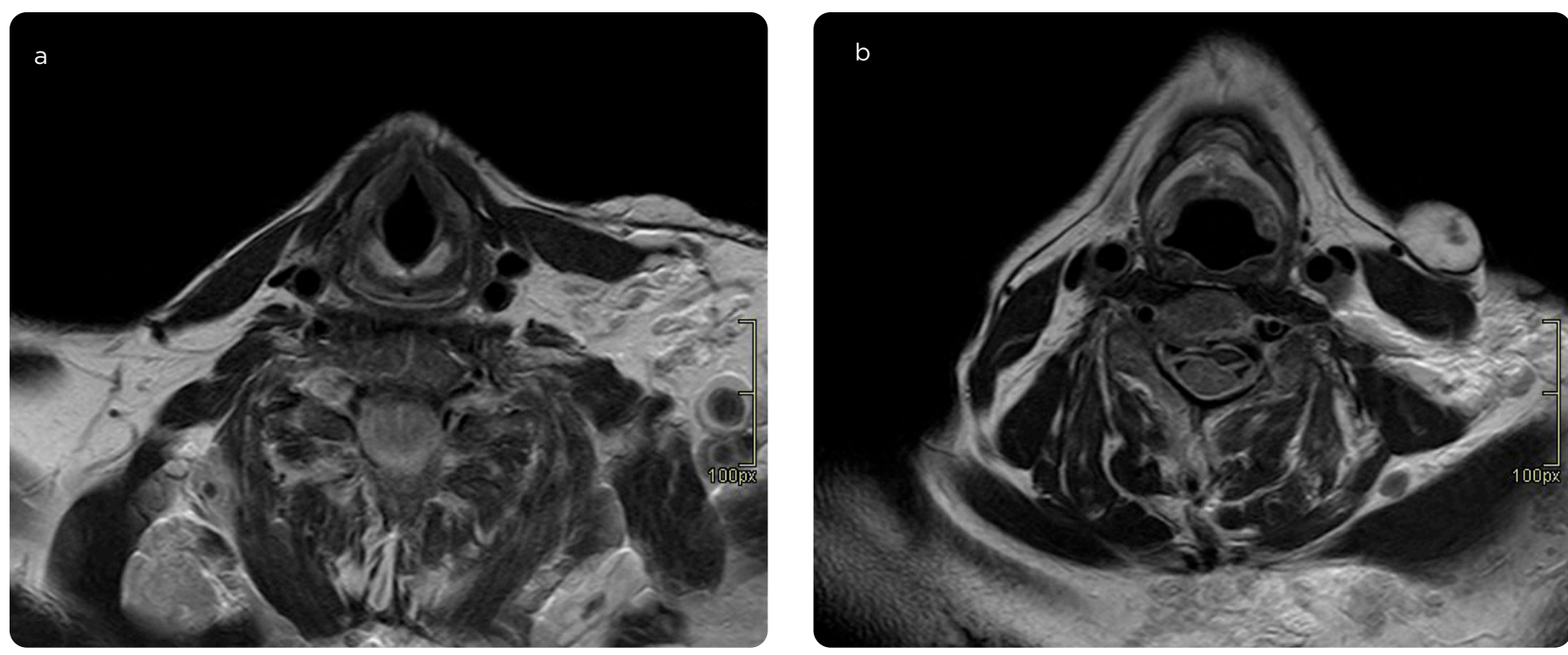

Figura 5. RM de cuello. a y b) Axial en secuencia con información T2: quiste epidermoide y áreas de alta señal en los músculos paraespinales. Flebolitos en tejidos blandos que originan artificio de susceptibilidad magnética por calcio. 
También se puede ofrecer como tratamiento la escleroterapia, la cual produce trombosis y necrosis de la malformación, por lo que se sugiere inyectar medio de contraste para caracterizar mejor la lesión, identificar su flujo y el drenaje de otras venas dentro de la lesión. Finalmente, la crioablación se ha descrito en la literatura como un método para llevar a cabo con guía ecográfica (7).

En conclusión, el paciente de este caso no solo tenía las lesiones características en la piel, sino también un extenso compromiso de tejidos blandos, con malformaciones vasculares en la pared torácica, el cuello, el brazo y el retroperitoneo. No obstante, más allá de la manifestación estética, el paciente no tuvo manifestaciones adicionales.

\section{Conclusión}

Las imágenes juegan un papel importante en el síndrome del nevus azul. Estas pueden ser el punto de partida para evidenciar — de manera incidental - esta patología, ya que es una enfermedad infrecuente y en algunos casos los pacientes cursan asintomáticos; también, son útiles para la caracterización de las lesiones cuando ya se han identificado al examen físico y, finalmente, mediante la radiología intervencionista se les puede proporcionar un manejo, como la escleroterapia. Otros tratamientos incluyen resección quirúrgica y crioablación. Es importante recordar que sus hallazgos principales corresponden a los característicos de malformaciones vasculares que, junto con lesiones macroscópicas en la piel, configuran el diagnóstico sindrómico. Aunque este paciente tenía alteraciones en los tejidos blandos y en la región retroperitoneal, uno de los sitios de afectación más común es el tracto gastrointestinal, que usualmente se visualiza mediante endoscopia de vías digestivas o enteroscopia y también, en estudios con bario o TAC, cuando las malformaciones causan intususcepciones o cualquier otra complicación y RM, que evidencia las lesiones en órganos como hígado, bazo y páncreas.

\section{Referencias}

1. Nahm WK, Moise S, Eichenfield LF, Paller AS, Nathanson L, Malicki DM, et al. Venous malformations in blue rubber bleb nevus syndrome: Variable onset of presentation. J Am Acad Dermatol. 2004;50(5 SUPPL.):101-6.

2. Agnese M, Cipolletta L, Bianco M, Quitadamo P, Miele E, Staiano A. Blue rubber bleb nevus syndrome. Acta Paediatr Int J Paediatr. 2010;99(4):632-5.

3. Suksamanapun N, Trakarnsanga A, Akaraviputh T. Blue rubber bleb nevus syndrome Endoscopy. 2011;43(SUPPL. 2):13-5.

4. Blue Rubber Bleb Nevus Syndrome. StatPearls. NCBI Bookshelf [Internet] [citado: 2020 nov. 27]. Disponible en: https://www.ncbi.nlm.nih.gov/books/ NBK541085/?report=classic

5. Kassarjian A, Fishman SJ, Fox VL, Burrows PE. Imaging characteristics of blue rubber bleb nevus syndrome. Am J Roentgenol. 2003;181(4):1041-8.

6. Dubois J, Alison M. Vascular anomalies: What a radiologist needs to know. Pediatr Radiol. 2010;40(6):895-905.

7. Hage AN, Beecham Chick JF, Srinivasa RN, Bundy JJ, Chauhan NR, Acord M, et al Treatment of venous malformations: The data, where we are, and how it is done. Tech Vasc Interv Radiol. 2018;21(2):45-54. doi: https://doi.org/10.1053/j.tvir.2018.03.001

\section{Correspondencia}

Paula Andrea Forero

Departamento de Imágenes Diagnósticas

Fundación Santa Fe de Bogotá

Bogotá, Colombia

paulaforero1129@gmail.com

Recibido para evaluación: 4 de febrero de 2021

Aceptado para publicación: 30 de abril de 2021 